\title{
Content and Language Integrated Learning (CLIL) Method and How It Is Changing the Foreign Language Learning Landscape
}

\author{
Nam Phuong Le, Phoebe Nguyen \\ Tiptop Academy, Vancouver, Canada \\ Email: lpnam@hotmail.com
}

How to cite this paper: Le, N.P. and Nguyen, P. (2022) Content and Language Integrated Learning (CLIL) Method and How It Is Changing the Foreign Language Learning Landscape. Open Access Library Journal, 9: e8381.

https://doi.org/10.4236/oalib.1108381

Received: January 19, 2022

Accepted: February 8, 2022

Published: February 11, 2022

Copyright $\odot 2022$ by author(s) and Open Access Library Inc.

This work is licensed under the Creative Commons Attribution International License (CC BY 4.0).

http://creativecommons.org/licenses/by/4.0/

\begin{abstract}
Global English language education is expanding rapidly. As a result, many approaches and strategies have been developed to improve the way to teach and learn languages. The purpose of this paper is to provide a brief literature review on a method that gaining popularity lately which is Content and Language Integrated Learning (CLIL). CLIL is a method of teaching a language by integrating non-language contents into the language lessons. The nonlanguage content can be anything ranging from science, social science to literature. Moreover, CLIL can be implemented from elementary school to the university level. CLIL has been proven to be effective for students to learn a new language. At the same time, it helps to develop other skills such as cognitive, cultural awareness, and general academic knowledge. The literature also pointed out several barriers to broadly implementing the CLIL method which are lack of qualified teachers and relevant resources. As a result, it is recommended that school administrators and policymakers should focus on teachers and resources development.
\end{abstract}

\section{Subject Areas}

Language Education

\section{Keywords}

Content and Language Integrated Learning, CLIL, Foreign Language Learning, ESL, EFL

\section{Introduction}

The globalization trend had intensified the importance of the English language. 
The global English language learning market has been growing rapidly as it is a widely spoken language for international communication [1]. As of 2019, there were 1.5 billion English language learners around the world and the number is expected to grow further [2]. There are two different types of learners English as a foreign language (EFL) and English as a second language (ESL). To distinguish the two, "EFL speakers generally are those using English occasionally for business or pleasure, while ESL students use English on a daily basis" [2]. To enhance the quality of English language education, various learning models have been developed such as Content-Based Instruction (CBI), English for Specific Purposes (ESP), English as the Medium of Instruction (EMI), and Content and Language Integrated Learning (CLIL) [3]. Of these models, CLIL has gained popularity lately and emerged to be one of the most effective methods to teach and learn a language [4] [5]. CLIL is a dual-focus method of education where students learn both the language and the subject content at the same time [6]. The purpose of this paper is to provide a summary of the current literature on the development and application of CLIL. This paper will provide basic guidance for language educators' school administrators, and policymakers to consider applying this method to enhance the quality of language education.

\section{Literature Review of Content and Language Integrated Learning (CLIL)}

According to Koç, Yüksel, and Altun (2021), CLIL is a method of integrating content for the purpose of learning a language [7]. The content can be any nonlanguage subjects such as science, history, literature, and so on [3]. This method of teaching had been formalized in the 1960s in Canada. CLIL method has been gaining popularity in Europe in the last 20 years [3] [7].

CLIL is considered an innovative method of teaching language. This educational method combines the language and content in order to develop the learners' language skills and specific knowledge at the same time. There is a 4Cs framework lining at the core of the CLIL method: Content, cognition, communication, and culture. First, students will learn the content from the language lesson. Second, CLIL helps to develop cognition skills: "To enable the learners to create their own interpretation of content, it must be analyzed for its linguistic demands" [1]. Third, communication is about learning the language in a different context. Lastly, culture awareness, as stated above is a critical component to advance in a foreign language [1].

Diab, Abdel-Haq, and Aly (2018) studied the effectiveness of CLIL for foreign language learning [1]. As stated in their research, learning the language, and learning the culture go hand-in-hand. It is almost impossible to learn a language without learning the culture surrounding that language. In fact, cultural awareness help to influence the way people speak. In the study, the authors conducted pre and post-test to determine the culture awareness development for the participants. The result of the study showed a significant improvement to the stu- 
dents' cultural awareness by implementing the CLIL method.

Sakellariou and Papadopoulos (2020) pointed out that almost all countries in Europe offer some types of CLIL courses. CLIL can be implemented from primary school up to the university level. The benefit of CLIL is that it does not require extra hours to spend on teaching and learning a language. Sakellariou and Papadopoulos's study is consistent with other studies which demonstrate the benefit of CLIL on student language and cognitive development. Furthermore, the CLIL method enables students to add a new language without losing their native ones. This method contributes to developing a positive attitude among the learners toward "plurilingualism" [5].

Harrop (2012) showed that CLIL students are more proficient and have better communication skills compared to non-CLIL students. Indeed, CLIL "leads to greater linguistic proficiency, it boosts motivation, it is suitable for learners of all abilities, and it leads to greater intercultural awareness" [8]. CLIL method also helps to increase the motivation among learners. Consistent with other studies, CLIL is an effective tool to help develop intercultural understanding. Additionally, CLIL provides an economical way to learn a language. This method of learning can help to prepare the future workforce for our Knowledge Economy nowadays as learners can gain both the language and specific knowledge at the same time.

Despite the numerous benefits that CLIL brings, there are some implementation problems for this method. One of the main difficulties for CLIL is to have teachers who have expertise in the subject area of instructions. The other difficulty is the "insufficient teaching resources" [7]. Harrop (2020) also pointed out the problem with a shortage of qualified teachers who have expertise in both the language and the subjects. Curriculum development is another issue [8]. As CLIL is gaining popularity around the world, Li et al. (2020) conducted a study to explore the curriculum development for this learning method. Their study indicated a lack of support and material for this learning method. Indeed, curriculum development is the key to having a high-quality language learning program. The key idea from their research includes: 1) curriculum development for CLIL should be transdisciplinary contain both the language and the content; 2) the development process should involve all stakeholders, 3) all stages in the curriculum development should be interconnecte [4].

Lastly, education technology combined with CLIL can be very beneficial. Lavrysh, Saienko, and Kyrychok (2021) conducted a study to examine the impact of technology on the authenticity of CLIL courses. The study showed that the implementation of technology is not only helped students to improve their language skills but also enhance their content knowledge. Furthermore, technologies also contribute positively to the four pillars of the CLIL learning model: content, cognition, communication, and culture [9].

CLIL can have great applications in many fields. As stated by Hussain (2019), CLIL can be integrated to enhance the quality of journalism. According to the 
author, the use of CLIL can lead to better curriculum design and enhanced material development [6]. Another study by Pancheva and Antov (2017) showed the benefits of CLIL within Engineering Education. This method of teaching and learning helps to improve the confidence level of the learners and enhanced the "academic cognitive processes and communication skills" [10]. Furthermore, students can learn more vocabulary. Consistent with Harrop (2012), CLIL students have better foreign language skills compared to traditional language learners [10]. Another application of CLIL is in the field of Physical Education (PE). By implementing the CLIL method, it helps students to improve their oral comprehension skills. Indeed, students have to use English to explain ideas, give instructions for activities, and communicate with peers [11].

\section{Conclusion}

In conclusion, CLIL is a method of teaching language by integrating content into the lessons. Students are not just learning the language but other subject knowledge at the same time. This method is effective and time-saving since it enables students to gain both language and subject area knowledge. In addition, CLIL provides a more natural way to learn a new language. Students who undertake the CLIL program are more proficient in the language compared to the traditional way of learning a language. CLIL also focuses on developing four competencies which are content, cognition, communication, and culture. There are some barriers to implementing this learning method such as lack of qualified teachers and teaching resources. In fact, it is harder to find language teachers that have expertise in the academic subject. Moreover, it will be a major task to develop teaching materials that blend language teaching and subject content together. However, in the long run, it is expected the widespread of CLIL can help to improve language teaching and learning around the world.

\section{Conflicts of Interest}

The authors declare no conflicts of interest.

\section{References}

[1] Diab, A.A.M., Abdel-Haq, E.M. and Aly, M.A.S. (2018) The Effectiveness of Using Content and Language Integrated Learning (CLIL) Approach to Enhance EFL Student Teachers' Cultural Awareness. https://eric.ed.gov/?id=ED582276

[2] Beare, K. (2020) How Many People Learn English? https://www.thoughtco.com/how-many-people-learn-english-globally-1210367

[3] Zemach, D. (2021) What Is CLIL? The Global Trend in Bilingual Education Explained. https://bridge.edu/tefl/blog/what-is-clil/

[4] Li, L., Huang, F., Chen, S., Pan, L., Zeng, W. and Wu, X. (2020) Exploring the Curriculum Development in Content and Language Integrated Learning: A Systematic Review. International Journal of Evaluation and Research in Education, 9, 11021113. https://doi.org/10.11591/ijere.v9i4.20705

[5] Sakellariou, G. and Papadopoulos, I. (2020) Interculturalism in Content and Language Integrated Learning Classes: Research Perspectives from European Policy to 
Greek Reality. Language Teaching Research Quarterly, 17, 45-54. https://doi.org/10.32038/ltrq.2020.17.04

[6] Hussain, S. (2019) It's Never Too Late to Mend: Potentials of CLIL Pedagogical Approach to Internationalize Ethiopian Journalism Education. Creative Education, 10, 2246-2269. https://doi.org/10.4236/ce.2019.1010162

[7] Koç, Ö., Yüksel, G. and Altun, E. (2021) Technology Acceptance and Usage Behaviour of Content and Language Integrated Learning Teachers in Turkey. English Language Teaching Educational Journal, 4, 113-124. https://doi.org/10.12928/eltej.v4i2.4269

[8] Harrop, E. (2012) Content and Language Integrated Learning (CLIL): Limitations and Possibilities. Encuentro, 21, 57-70.

[9] Lavrysh, Y., Saienko, N. and Kyrychok, A. (2021) Issues of Educational Technologies and Authenticity Synergy in a Content and Language Integrated Learning Course at Technical University. International Journal of Emerging Technologies in Learning (IJET), 16, 113-128. https://doi.org/10.3991/ijet.v16i14.21237

[10] Pancheva, T. and Antov, P. (2017) Application of Content and Language Integrated Learning (CLIL) in Engineering Education. Management and Sustainable Development, 63, 36-40.

[11] Coral, J. and Lleixà, T. (2016) Physical Education in Content and Language Integrated Learning: Successful Interaction between Physical Education and English as a Foreign Language. International Journal of Bilingual Education and Bilingualism, 19, 108-126. https://doi.org/10.1080/13670050.2014.977766 